\title{
Studies on Porphobilinogen
}

\author{
By PHYLLIS E. BROCKMAN AND C. H. GRAY \\ Department of Chemical Pathology, King's College Hospital, London, S.E. 5
}

(Received 6 August 1952)

The term porphobilinogen will be used in the present paper for the colourless chromogen excreted in acute porphyria, often in association with free porphyrins, their metal complexes and other pigments, and responsible for the reaction with $p$-dimethylaminobenzaldehyde (Ehrlich's aldehyde reagent) giving a chloroform-insoluble red pigment. The chromogen itself has not yet been isolated, but crude solutions have been prepared by chromatography and shown to form in acid solution a mixture of porphyrins and porphobilin, a highly polar bile pigment with properties resembling urobilin (Waldenström \& Vahlquist, 1939a; Prunty, 1945). Waldenström \& Vahlquist, on the basis of molecular weight determinations by the diffusion method, proposed that porphobilinogen was a dipyrryl compound, two molecules of which could condense together to give a bile pigment or, in accordance with the theory of Dobriner, Strain \& Localio (1937), a porphyrin. Neuberger, Muir \& Gray (1950) have emphasized that such a mechanism was unlikely to give rise to naturally occurring porphyrins which are of types I and III only.

Recently, Hawkinson \& Watson (1952) and also Herbert (1952) have observed that ethyl acetate extracts of porphyria urines contained a colourless porphyrin precursor not reacting with $p$-dimethylaminobenzaldehyde but forming a porphyrin on irradiation with ultraviolet light or on oxidation. The work of Herbert may be interpreted as suggesting that the increased amounts of porphyrin obtained on heating crude acidified porphyria urines were due to the formation of porphyrin from this precursor as well as from porphobilinogen. However, Lowry, Schmid, Hawkinson, Schwartz \& Watson (1950) claim to have prepared solutions of porphobilinogen which, on heating in acid, formed only porphobilin, and their work implies that porphobilinogen is a precursor of porphobilin only, and that solutions of porphobilinogen which give rise to porphyrin must contain a porphyrin precursor as an impurity.

It appeared of interest to determine the effect of heating on the absorption spectrum of porphobilinogen solutions under various conditions, for Grieg, Askevold \& Sveinsson (1950) have shown that maximum yields of porphyrin from porphyria urines are obtained only if the urines are heated at $100^{\circ}$ at $\mathrm{pH} 5 \cdot 2$, while Herbert (1952) has shown that porphyrin formation from porphobilinogen solutions is greatest in $0.05-0.2 \mathrm{~N}$-hydrochloric acid. We have found that solutions of porphobilinogen prepared chromatographically give rise to at least three pigments, a porphyrin, a yellow pigment and a violet pigment, the yield of each depending on the conditions. In four urines examined we have found no evidence of the presence of a porphyrin precursor other than porphobilinogen.

Preliminary reports of this work have already been communicated to the Biochemical Society (Gray, 1951; Brockman \& Gray, 1951, 1952).

\section{MATERIALS AND METHODS}

Porphobilinogen solution. Porphyria urines containing 5-10 units of porphobilinogen/ml. were chromatographed five times through alumina by the method of Prunty (1945). The units are those of Prunty (1945). Each eluate was brought to $\mathrm{pH} 6.8$ with $20 \%(\mathrm{w} / \mathrm{v}) \mathrm{NaOH}$, the white precipitate was removed by centrifugation, and the solution was stored in the refrigerator until it could be rechromatographed. The final neutralized eluate contained 10-15 units of porphobilinogen/ml., i.e. it was very little more concentrated than the original urine but contained less than $0.01 \mathrm{mg}$. of urea $/ \mathrm{ml}$. This neutralized eluate was used throughout the work except where stated otherwise. In some later experiments the final porphobilinogen eluate in $1 \%$ acetic acid was freeze-dried to give a stable, white powder containing 4 units of porphobilinogen/mg., approximately $1 \%$ of uric acid, a trace of amino-acid and much sodium acetate which presumably arose as a result of neutralizing the eluates with $\mathrm{NaOH}$.

Uricase. This was kindly supplied as a suspension in glycine buffer, pH 9·4, by Dr E. Praetorius of Copenhagen. The concentration of the enzyme in the suspension was unknown.

Glycine buffer. This buffer, pH 9·4, 0.66 M, was prepared as described by Praetorius (1949).

Acetate buffers. These were prepared according to Cole (1933).

Veronal-acetate buffer. $\mathrm{pH} 9 \cdot 3$. This was the modification by Neuberger \& Scott (1952) of that described by Michaelis (1931).

Spectral absorption. This was measured in a Hilger Uvispek photoelectric spectrophotometer.

pH Measurements. These were made with a Cambridge pH meter using a glass electrode.

Porphobilinogen concentration. This was measured in units as described by Prunty (1945) using the $p$-dimethylaminobenzaldehyde reagent of Waldenström \& Vahlquist (1939b). 


\section{EXPERIMENTAL AND RESULTS}

\section{Absorption spectrum of porphobilinogen solutions free from uric acid}

Before the removal of uric acid the colourless porphobilinogen solution showed only a strong absorption maximum in the ultraviolet at $292 \mathrm{~m} \mu$. (Fig. 1). The result of uricase

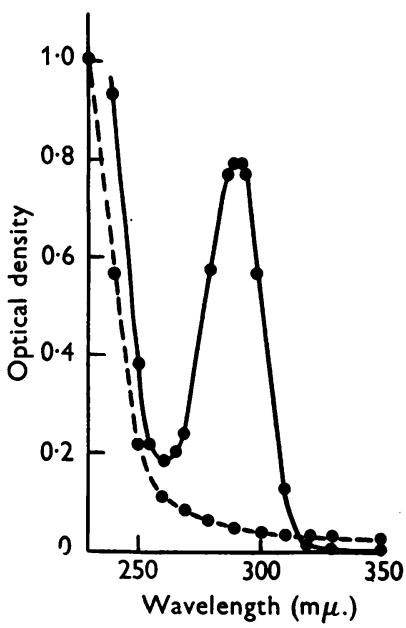

Fig. 1. Absorption spectrum of porphobilinogen solution in $0.066 \mathrm{M}$-glycine buffer, $\mathrm{pH} 9 \cdot 4$. $\longrightarrow$, before destruction of uric acid; - - , after destruction of uric acid by the addition of $0.01 \mathrm{ml}$. uricase suspension $/ 3 \mathrm{ml}$. of porphobilinogen solution. Suitable blanks of $0.066 \mathrm{M}$-glycine buffer, pH 9.4, without and with added uricase were used.

treatment was to abolish all absorption at wavelengths longer than $250 \mathrm{~m} \mu$. The absorption in the region of $290 \mathrm{~m} \mu$., which previously was regarded as due to porphobilinogen, was obviously due to uric acid.

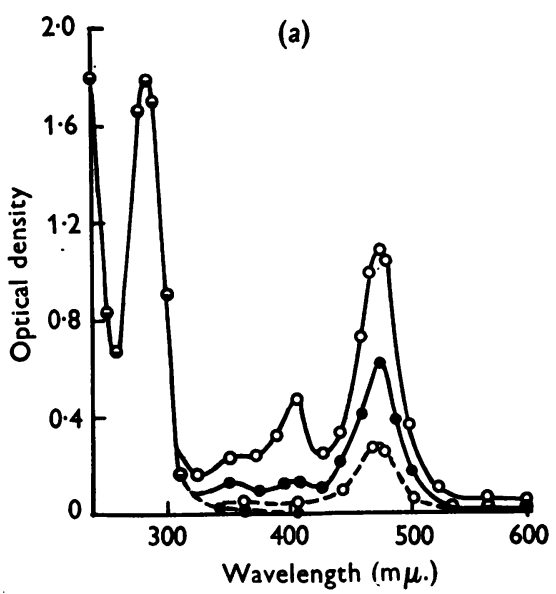

\section{Changes in absorption spectrum on heating porphobilinogen solutions at $\mathrm{pH} \mathbf{5 \cdot 2}$}

After heating for 1-2 min. the porphobilinogen solution became yellow and showed two absorption maxima, a strong one at $477-480 \mathrm{~m} \mu$. and a much weaker one in the region of 350-370 $\mathrm{m} \mu$. (Fig. 2a). On heating for a further $3 \mathrm{~min}$. the absorption at these wavelengths increased and a new maximum appeared at $407 \mathrm{~m} \mu$. At this stage the solution fluoresced red in ultraviolet light. On further heating the solution became pink and the two absorption bands at 350-370 and 477-480 $\mathrm{m} \mu$. diminished in intensity. At the same time the $407 \mathrm{~m} \mu$. band increased in intensity and reached its maximum after about $40 \mathrm{~min}$. heating (Fig. $2 b$ ). After 70 min. heating (curve not shown in Fig. 2b) the absorption at $480 \mathrm{~m} \mu$. was diminished further in intensity; that at $407 \mathrm{~m} \mu$. was also diminished. There was no change in the absorption due to uric acid which at $\mathrm{pH} 5 \cdot 2$ is at 286-288 $\mathrm{m} \mu$.

The absorption maximum at $407 \mathrm{~m} \mu$. was undoubtedly the Soret band of a porphyrin, for the intensity of this band increased in proportion to the red fluorescence in ultraviolet light. The position of this absorption maximum and the ether-insolubility of the porphyrin is not incompatible with its being uroporphyrin.

Effect of molarity. When freeze-dried porphobilinogen was

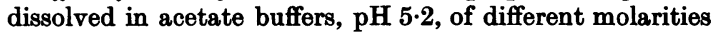
and heated, red precipitates were formed. Fig. $3 a$ and $b$ show the absorption spectra of the supernatant solutions, and of the solutions of the precipitates in $0.5 \mathrm{~N}-\mathrm{HCl}$. In $0.1 \mathrm{~m}$ buffer the supernatant showed no significant absorption at wavelengths above $350 \mathrm{~m} \mu$., but the acid solutions of the precipitates showed absorption maxima at 407 and 480-500 $\mathrm{m} \mu$. In $\mathrm{M}$ buffer the supernatant showed an absorption maximum at $\mathbf{4 8 0} \mathrm{m} \mu$. only, and the acid solutions of the precipitates showed maxima at 407 and $480 \mathrm{~m} \mu$.

The differences in spectra of supernatant and of acid solutions of the precipitate cannot be due to differences in $\mathrm{pH}$ of the solutions. None of the supernatants contained

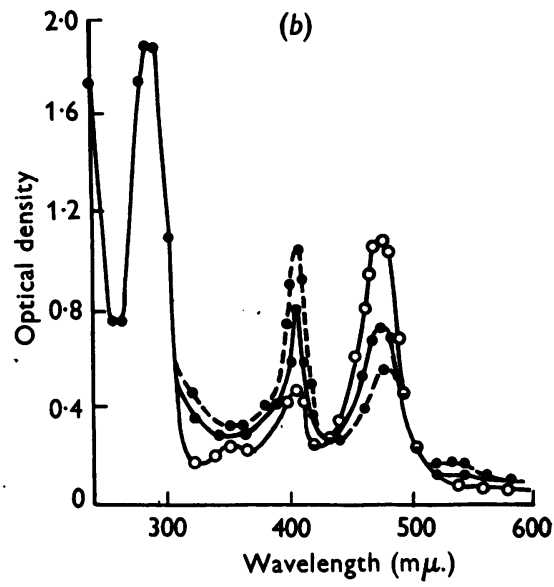

Fig. 2. Changes in absorption spectrum on heating porphobilinogen solutions at $\mathbf{p H}$ 5.2. Porphobilinogen solution, stored at $\mathrm{pH} 6 \cdot 8$ at $0^{\circ}$ was diluted with an equal volume of $2 \mathrm{M}$-acetate buffer, $\mathrm{pH} \mathrm{5 \cdot 2}$. Samples were heated in a boiling-water bath for the times specified, and immediately cooled. (a) - - - , before heating; $\mathrm{O}_{-}-\mathrm{O}$, after heating for $1 \mathrm{~min}$.; - , after heating for 2 min.; $O-O$, after heating for 5 min. (b) $\mathrm{O}-\mathrm{O}$, after heating for 5 min.; -0 , after heating for $20 \mathrm{~min} . ;$ 
any porphyrin as judged by the absence of absorption at $407 \mathrm{~m} \mu$. The pH's of supernatants and acid solutions were 5.2 and 1.0 respectively, both well on the acid side of the apparent dissociation constant of the yellow pigment (see below). The difference between the effects of heating in the two buffers may therefore be shown by plotting a composite curve obtained by summation of the optical density of each supernatant with that of the corresponding precipitate dissolved in $0.5 \mathrm{~N}-\mathrm{HCl}$ (Fig. $3 \mathrm{c}$ ).

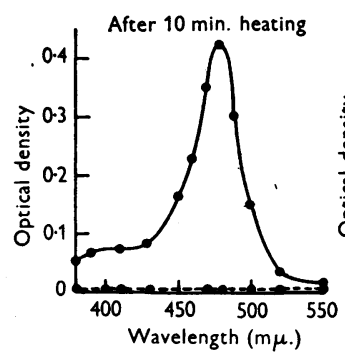

(a) After 50 min. heating
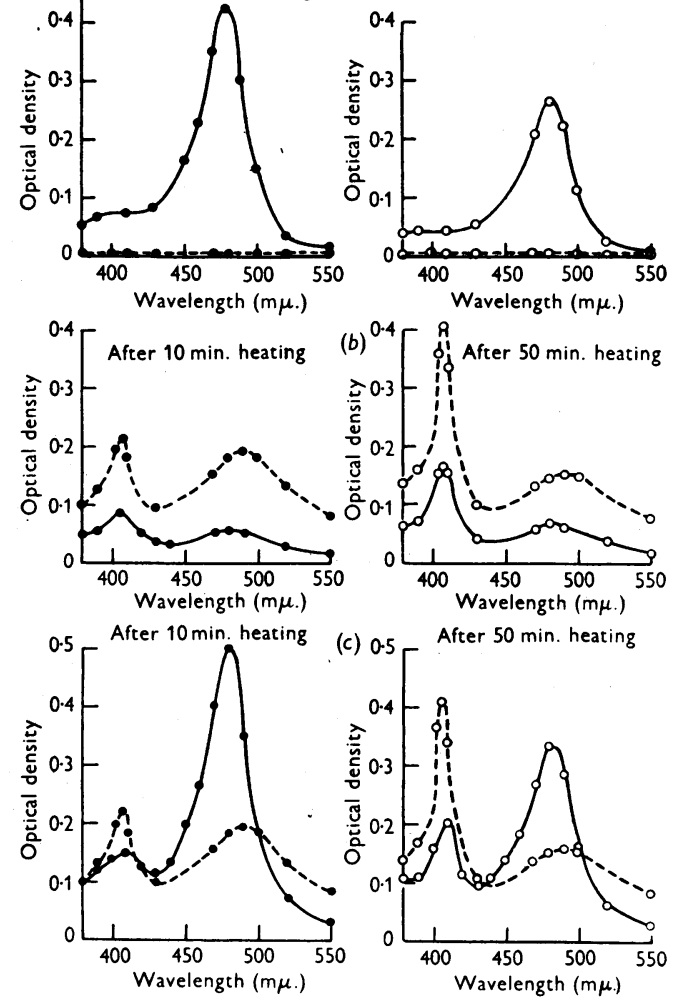

Fig. 3. Changes in absorption spectra on heating porphobilinogen solutions in $0 \cdot 1 \mathrm{M}$ - and $\mathrm{M}$-acetate buffer, $\mathrm{pH} 5 \cdot 2$. (a) Spectral absorption of supernatants; (b) spectral absorption of acid solutions of precipitates; $(c)$ composite curves obtained by summing the optical densities in the supernatants given in $(a)$ and the acid solutions of the precipitates given in $(b)$. - - after $10 \mathrm{~min}$. heating in $0 \cdot 1 \mathrm{~m}$-acetate buffer; - after $10 \mathrm{~min}$. heating in M-acetate buffer; $\mathrm{O}---\mathrm{O}$, after $50 \mathrm{~min}$. heating in $0.1 \mathrm{M}$ acetate buffer; $\mathrm{O}-\mathrm{O}$, after $50 \mathrm{~min}$. heating in $\mathrm{M}$ acetate buffer.

In both $\mathrm{M}$ and $0.1 \mathrm{M}$ buffers the absorption in the region of $480 \mathrm{~m} \mu$. was at its maximum after $10 \mathrm{~min}$. heating, but in the stronger buffer it was twice as intense as that in the weaker buffer. The maximum yield of porphyrin was obtained in both solutions after $50 \mathrm{~min}$. heating, but the yield in the $0.1 \mathrm{M}$ buffer was twice as great as that obtained in the M buffer. A slightly greater proportion of porphyrin was formed when the freeze-dried porphobilinogen was heated in water, the salts present sufficing to give a pH of $5 \cdot 2$. With solutions of molarities between $0.1 \mathrm{M}$ and $\mathrm{m}$ the yields of the two pigments were intermediate between those obtained in the $0.1 \mathrm{M}$ and $\mathrm{M}$ buffers. Increasing concentrations of acetate thus appeared to decrease the porphyrin yield with a proportionate increase in the yield of the yellow pigment.

When freeze-dried porphobilinogen was dissolved in $\mathbf{M -}$ and $0.1 \mathrm{M}$-formate and propionate buffers, $\mathrm{pH} \mathrm{5.2,} \mathrm{and}$ heated, the results were similar to those obtained in the corresponding $\mathrm{M}$ - and $0 \cdot 1 \mathrm{M}$-acetate buffers.

Rate of disappearance of Ehrlich reaction. Fig. 4 shows the intensity of the Ehrlich reaction after heating (for different times) the freeze-dried porphobilinogen dissolved in water, and in $\mathrm{M}$-acetate buffer, $\mathrm{pH} 5 \cdot 2$, i.e., conditions under which porphyrin and yellow pigment production predominate, respectively. Fig. $5 a$ and $b$ show the percentage disappearance of porphobilinogen plotted against the corresponding intensities of the spectral absorption at 407 and $480 \mathrm{~m} \mu$. Porphobilinogen disappearance was apparently directly proportional to porphyrin formation in the acetate buffer, but low optical densities resulted in a considerable experimental error. Porphobilinogen disappearance was clearly not directly proportional to porphyrin formation in water, or to yellow pigment formation in either water or buffer. Analysis of the two curves reveals that the reaction

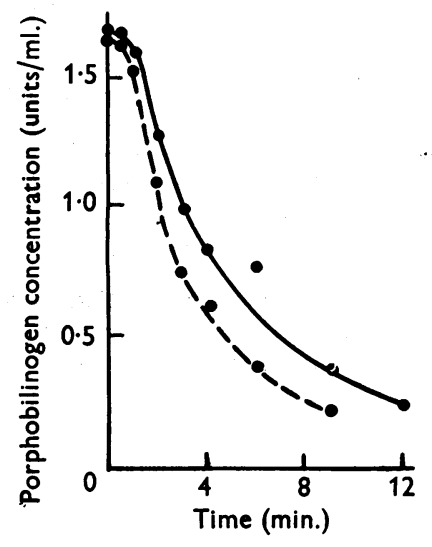

Fig. 4. Rate of disappearance of the Ehrlich reaction on heating freeze-dried porphobilinogen dissolved in: $\bigcirc$, water; - - - M-acetate buffer, pH 5.2. Samples were removed after convenient intervals for the determination of porphobilinogen concentration and of spectral absorption.

concerned with the disappearance of porphobilinogen whether in water or in buffer is neither first order nor second order.

\section{Changes in absorption spectrum on heating porphobilinogen solutions in $\mathrm{HCl}$}

The series of changes occurring on heating in acid were similar to those represented in Fig. $2 a$ and $b$ for solutions at pH 5.2, except that maximum porphyrin formation, as indicated by the height of the absorption band at $407 \mathrm{~m} \mu$., occurred after only $10 \mathrm{~min}$. heating. The yield of porphyrin was greatest in $0.05-0.2 \mathrm{~N} \cdot \mathrm{HCl}$ and was twice as great as the maximum yield obtained in water at $\mathrm{pH} 5 \cdot 2$. These obser- 
vations agree with the recent findings of Herbert (1952). In acid more concentrated than $0 \cdot 2 \mathrm{~N}$ the porphyrin appeared to be rapidly destroyed on heating. The yield of yellow pigment as indicated by the height of the 477-480 $\mathrm{m} \mu$. band was greatest in $2 \mathrm{~N}-\mathrm{HCl}$, and was approximately equal to the maximum yield obtained in $\mathbf{M - a c e t a t e}$ buffer. While this of a spectrophotometrically detectable dissociation. The alkaline eluate was diluted with an equal volume of veronalacetate buffer, pH 9.3, and the changes in spectral absorption were determined when the $\mathrm{pH}$ of the solution was varied by the addition of either $0.1 \mathrm{~N}-\mathrm{HCl}$ or $0.1 \mathrm{~N}-\mathrm{NaOH}$ to samples of the buffered solution. In each case the solution (a) In water

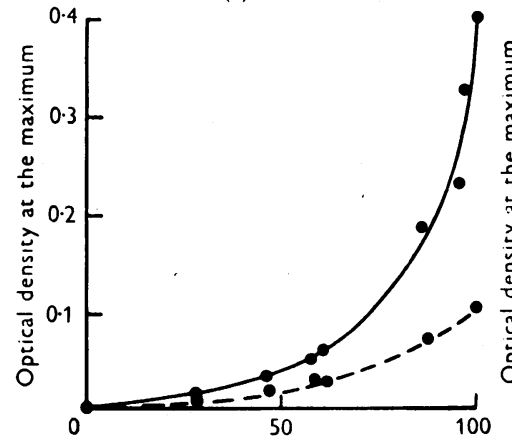

(b) In M-acetate buffer, $\mathrm{pH} 5 \cdot 2$

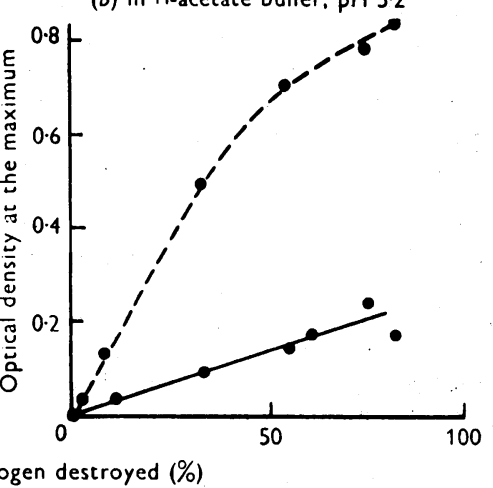

Fig. 5. Disappearance of porphobilinogen with formation of porphyrin and yellow pigment. The intensity of the Ehrlich reaction is expressed as the percentage of porphobilinogen destroyed. The porphyrin and yellow pigment are expressed in terms of their optical densities at 407 and $480 \mathrm{~m} \mu$., respectively. - , porphyrin; --1 , yellow pigment.

would suggest that the porphyrin decomposes under these conditions to form the yellow pigment, this appears unlikely in view of the more complete investigation carried out at $\mathrm{pH} 5 \cdot 2$.

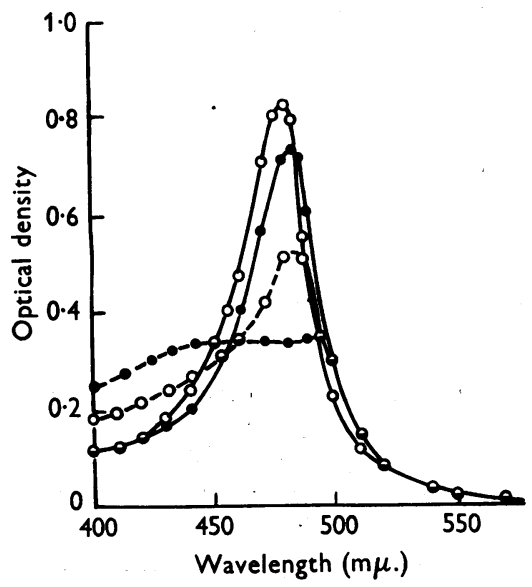

Fig. 6. Effect of $\mathrm{pH}$ on the absorption spectrum of the yellow pigment. $\bigcirc-\mathrm{O}, \mathrm{pH} \mathrm{2.2}$; O- - O, pH 9.3; - - - , pH 10.2.

\section{Properties of the yellow pigment}

The yellow solutions obtained after heating various porphobilinogen solutions at $\mathrm{pH} \mathrm{5.2}$ for 5-10 min. were united and passed through an alumina column. The yellow pigment which stayed at the top of the column was eluted with $0 \cdot 35 \%(w / v) \mathrm{NH}_{3}$.

The eluate was greenish yellow in alkaline solution but changed to a pinkish yellow in acid, suggesting the existence was made to constant volume with distilled water. No attempt was made to maintain constant ionic strength.

In solutions of $\mathrm{pH}$ less than 4, the yellow pigment had a strong absorption maximum at $477-478 \mathrm{~m} \mu$., but as the

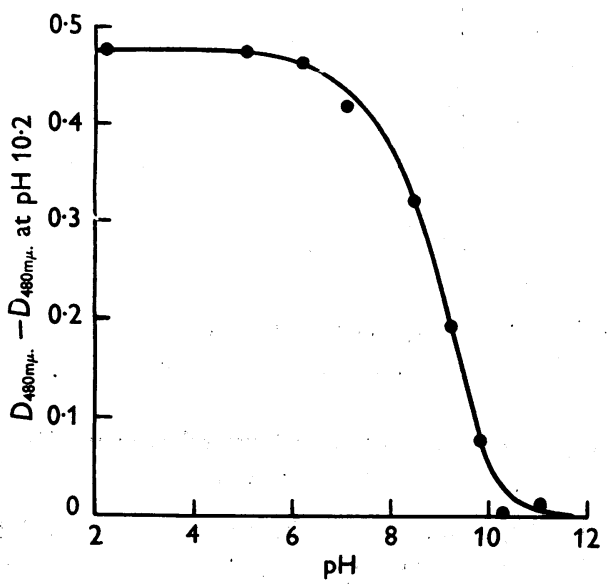

Fig. 7. Spectrophotometric titration curve of the yellow pigment. $D_{480 \mathrm{~m} \mu .}=$ optical density at $480 \mathrm{~m} \mu$. at observed $\mathrm{pH} ; D_{480 \mathrm{~m} \mu}$. at $\mathrm{pH} 10 \cdot 2=$ optical density at $480 \mathrm{~m} \mu$., when the $\mathrm{pH}$ was $10 \cdot 2$. This was the lowest optical density recorded.

pH was increased the maximum gradually shifted to 483$484 \mathrm{~m} \mu$. and the optical density decreased. In very alkaline solutions a second small peak appeared at 49.5-497 $\mathrm{m} \mu$. (Fig. 6). The spectrophotometric titration curve (Fig. 7) shows that the apparent $\mathrm{pK}$ of the yellow pigment is 9.0. 
The ability of the yellow pigment to give rise to porphyrin on heating has been studied. The alkaline eluate was brought to $\mathrm{pH} 5.2$ and samples were heated for 10 and $30 \mathrm{~min}$. respectively. A yellow precipitate was formed, but the absorption curves of the precipitate dissolved in $0.5 \mathrm{~N}$ $\mathrm{HCl}$ and of the corresponding supernatant showed a maximum only at $480 \mathrm{~m} \mu$. The absence of red fluorescence and of an absorption maximum in the region $407 \mathrm{~m} \mu$. showed that no porphyrin was formed. The yellow precipitate was found to be insoluble in all organic solvents. After treating with methanolic $\mathrm{HCl}$ it was possible to extract most of the pigment with $\mathrm{CHCl}_{3}$. Attempts to crystallize the $\mathrm{CHCl}_{3}$-soluble pigment have not so far been successful.

The yellow solution gave an intense green fluorescence when added to ethanolic zinc acetate, a reaction characteristic of a dipyrrylmethene and certain tetrapyrrolic compounds. It failed to couple with diazotized sulphanilic acid showing that all carbon atoms of any pyrrole rings present must bear substituents. The colourless solution obtained on reduction with $2.5 \%$ sodium amalgam failed to react with Ehrlich's aldehyde reagent but reformed the original yellow pigment on acidification. Dehydrogenating agents such as $\mathrm{I}_{2}, \mathrm{FeCl}_{3}$, and $\mathrm{H}_{2} \mathrm{O}_{2}$ were without effect.

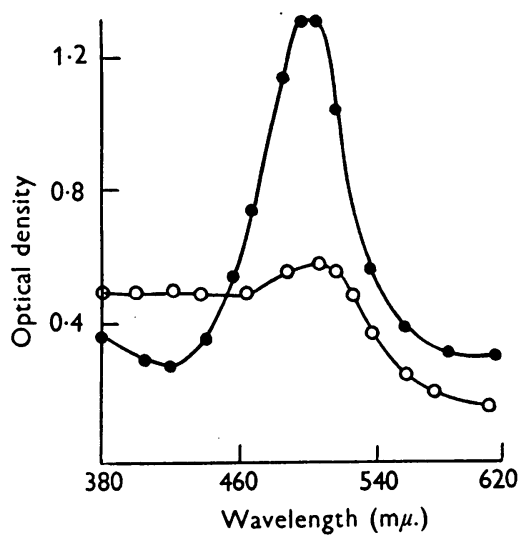

Fig. 8. Effect of $\mathrm{pH}$ on the absorption spectrum of the violet pigment. $-\mathrm{pH} 1 ; \mathrm{O}-\mathrm{O}, \mathrm{pH}>10$.

\section{Changes in absorption spectrum of porphobilinogen solutions at $\mathrm{pH} 1$}

HCl (10N) was added to the porphobilinogen solution, $\mathrm{pH} 6 \cdot 8$, until the concentration of acid was $7 \%(\mathrm{w} / \mathrm{v})$ and the $\mathrm{pH}$ was less than 1. On standing, the solution became violet and this change was accelerated by sunlight or ultraviolet light. The solution was left to stand until the reaction with $p$-dimethylaminobenzaldehyde was negative. The porphobilinogen concentration and the spectral absorption were determined at 24-hourly intervals. Since neither temperature nor exposure to light was controlled, it was impossible to investigate the order of the reaction. The violet solution possessed an absorption maximum at 503$505 \mathrm{~m} \mu$. (Fig. 8) and showed no fluorescence in ultraviolet light. The rate of formation of the violet pigment was directly proportional to the rate of disappearance of the Ehrlich reaction (Fig. 9).

\section{Properties of the violet pigment}

The solution gave no fluorescence with zinc acetate and did not react with diazotized sulphanilic acid. Reduction with $2.5 \%$ sodium amalgam gave a colourless solution which did not give an Ehrlich reaction but rapidly reformed the violet pigment in acid. The violet solution was unaffected by dehydrogenating agents. When heated at $\mathrm{pH} 5 \cdot 2$ a violet

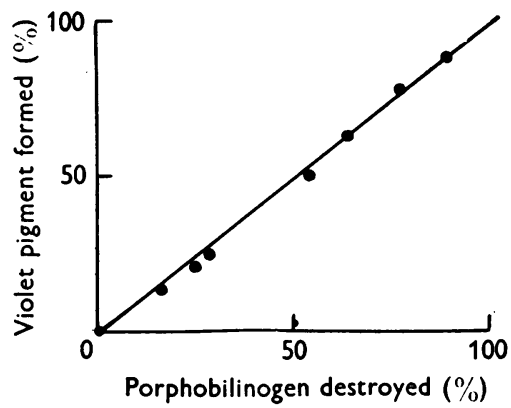

Fig. 9. Disappearance of porphobilinogen with formation of violet pigment. The intensity of the Ehrlich reaction is expressed as the percentage of porphobilinogen destroyed. The absorption at $504 \mathrm{~m} \mu$. is expressed as the percentage of violet pigment formed, taking the absorption to be $100 \%$ when the Ehrlich reaction had become negative.

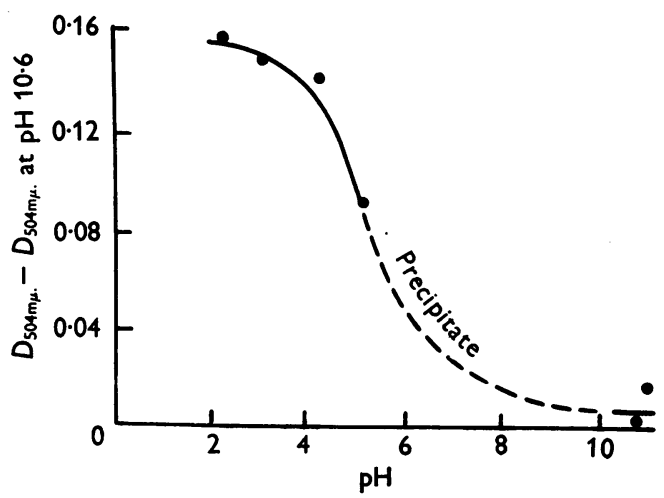

Fig. 10. Spectrophotometric dissociation curve of the violet pigment. $D_{504 \mathrm{~m} \mu \text {. }}=$ optical density at $504 \mathrm{~m} \mu$. at observed $\mathrm{pH} ; D_{504 \mu \mathrm{m}}$ at $\mathrm{pH} 10 \cdot 6=$ optical density at $504 \mathrm{~m} \mu$. when the $\mathrm{pH}$ was 10.6. This was the lowest optical density recorded.

precipitate was formed which when dissolved in $7 \%(\mathrm{w} / \mathrm{v})$ $\mathrm{HCl}$ showed only a maximum at 503-505 $\mathrm{m} \mu$. As the $\mathrm{pH}$ of the solution was increased the solution turned red-brown and the optical density at the maximum decreased (Fig. 8). It was not possible to study the dissociation spectrophotometrically as was done with the yellow pigment because a violet precipitate was formed at $\mathrm{pH}$ 's between 5 and 8 , but it appeared that there was a dissociation with a $\mathrm{pK}$ of about 5-6 (Fig. 10). The violet precipitate was insoluble in all organic solvents, but after treating with methanolic $\mathrm{HCl}$ it was possible to extract the coloured material with $\mathrm{CHCl}_{3}$. The neutral $\mathrm{CHCl}_{3}$ solution gave no fluorescence with zinc acetate. Attempts to crystallize the $\mathrm{CHCl}_{3}$-soluble pigment have so far not been successful. 


\section{Attempted purification of the porphyrin formed} from porphobilinogen solutions

The solutions obtained after heating various porphobilinogen solutions for 40-60 min. were combined and the porphyrin was adsorbed on to $\mathrm{Ca}_{3}\left(\mathrm{PO}_{4}\right)_{2}$ (Sveinsson, Rimington \& Barnes, 1949). The $\mathrm{Ca}_{3}\left(\mathrm{PO}_{4}\right)_{2}$ precipitate was dissolved in methanolic $\mathrm{HCl}$ and the ester obtained in $\mathrm{CHCl}_{3}$ solution by the customary methods. The porphyrin was taken up in benzene and purified by adsorption on an alumina column followed by elution with benzene- $\mathrm{CHCl}_{3}$ and $\mathrm{CHCl}_{3}$-methanol mixtures. Insufficient material was obtained for crystallization or for determination of the wavelength of the absorption bands in the visible region. The wavelength of the Soret band of the porphyrin ester in $\mathrm{CHCl}_{3}$ was $405 \mathrm{~m} \mu$.

\section{Investigation of a possible ethyl acetate-soluble porphyrin precursor}

The method of extraction used was that described by Watson (1951) and Hawkinson \& Watson (1952). Freshly passed porphyria urine $(500 \mathrm{ml}$.), having a porphobilinogen content of at least $10 \mathrm{units} / \mathrm{ml}$., was brought to $\mathrm{pH} 4$ with glacial acetic acid and extracted three times with $100 \mathrm{ml}$. of ethyl acetate. The ethyl acetate extract was washed repeatedly with $2 \%$ sodium acetate solution until the ethyl acetate no longer gave any reaction with $p$-dimethylaminobenzaldehyde. It was then washed with $1.5 \mathrm{~N}-\mathrm{HCl}$ until the acid no longer fluoresced red in ultraviolet light. The ethyl acetate extract was irradiated with ultraviolet light for periods varying from 10 to $60 \mathrm{~min}$., and then extracted with $1.5 \mathrm{~N}-\mathrm{HCl}$. In four porphyria urines thus studied the ethyl acetate extracts, even though entirely free of Ehrlich-reacting material, turned pink on irradiation in ultraviolet light but did not show a red fluorescence. The pink $1.5 \mathrm{~N}-\mathrm{HCl}$ extract of the irradiated ethyl acetate extract showed an absorption maximum at about $490 \mathrm{~m} \mu$. but did not fluoresce.

The urine remaining after the ethyl acetate extraction was chromatographed on alumina. The eluate which reacted with $p$-dimethylaminobenzaldehyde was brought to $\mathrm{pH} 5-6$, irradiated with ultraviolet light for $5 \mathrm{~min}$. and subjected to the Sveinsson, Rimington \& Barnes $\mathrm{Ca}_{3}\left(\mathrm{PO}_{4}\right)_{2}$ adsorption technique for the removal of any porphyrin which might have been formed. The resulting solution was brought to pH 5.2, heated for $30 \mathrm{~min}$., and was then found to contain porphyrin as judged by a red fluorescence in ultraviolet light and by the presence of absorption in the region $405-410 \mathrm{~m} \mu$.

In the four urines studied there was no evidence of the presence of the ethyl acetate-soluble Ehrlich non-reacting precursor. Moreover, porphobilinogen solutions formed porphyrin on heating even though subjected to the procedure alleged by Watson to remove such a precursor.

\section{DISCUSSION}

On heating porphobilinogen solutions at $\mathrm{pH} 5 \cdot 2$ for 5-10 min. a yellow pigment with an absorption maximum at $480 \mathrm{~m} \mu$. was formed. On longer heating this absorption maximum decreased with the appearance of the absorption band at $407 \mathrm{~m} \mu$. suggesting that porphobilinogen might first give rise to the yellow pigment which was then converted to porphyrin. However, when the chromatographically separated yellow pigment was heated at $\mathrm{pH} \mathrm{5.2} \mathrm{the} \mathrm{maximum} \mathrm{at} 480 \mathrm{~m} \mu$. decreased, but no porphyrin was formed. It seemed likely therefore that both the yellow pigment and the porphyrin were formed simultaneously, the latter more slowly than the former which was destroyed on prolonged heating.

On standing in acid at $\mathrm{pH} 1$ a violet pigment with a maximum absorption at 503-505 $\mathrm{m} \mu$. was formed. It is possible that a porphyrin labile in light was formed during the experiment and was destroyed as fast as it was formed. Whilst pure coproporphyrin and uroporphyrin are stable under these conditions it is known that porphyrins derived from porphyria urines may on occasion be unstable. The appearance of the pigment could be correlated with the disappearance of porphobilinogen, which suggests that this was the only pigment formed in these circumstances. It is possible that the violet pigment was formed in the heating experiments, and its absorption was masked by the greater absorption of the yellow pigment at $480 \mathrm{~m} \mu$. When porphobilinogen solutions were heated in $0.1 \mathrm{~m}$ buffer,

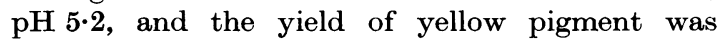
relatively small (Fig. 3) an absorption band was present in the solution of the precipitate in $0.5 \mathrm{~N}$ $\mathrm{HCl}$ with its maximum at $490-495 \mathrm{~m} \mu$. However, the supernatants of the porphobilinogen solutions heated in $\mathrm{M}$ buffer, $\mathrm{pH} \mathbf{5 \cdot 2}$, had absorption maxima at $480 \mathrm{~m} \mu$. Inspection of the curves in Fig. 6 shows that this shift in the absorption is in the opposite direction to that which would be expected for such a difference in $\mathrm{pH}$. It is more likely that the position of the maximum is due to the presence of a mixture of the yellow and violet pigments.

Porphobilinogen, therefore, appears to give rise to at least three distinct pigments, a porphyrin, a yellow pigment with maximum absorption at $480 \mathrm{~m} \mu$. and a violet pigment with maximum absorption at 503-505 $\mathrm{m} \mu$., the yields of each depending on the conditions. Porphobilin was described by Waldenström \& Vahlquist as a red pigment with an absorption maximum at about $500 \mathrm{~m} \mu$., properties in agreement with those found for the violet pigment rather than the yellow pigment.

In the absence of further knowledge it is impossible to do more than speculate upon the nature of porphobilinogen and of the yellow and violet pigments. The inability of these substances to pass from aqueous solutions into organic solvents except after esterification suggests that all have side chains bearing carboxyl groups and also that other hydrophilic groups are unlikely to be present. Monopyrrolic compounds, and compounds containing more than one unconjugated pyrrole ring, e.g. dipyrrlmethanes, the absorption spectra of which 
have been examined, have absorption maxima between 250 and $280 \mathrm{~m} \mu$. (Pruckner \& Dobeneck, 1942). Introduction of ethyl or carbethoxy groups displaces absorption towards longer wavelengths. It is therefore difficult to reconcile the absence of absorption of light of wavelengths greater than $240 \mathrm{~m} \mu$. by porphobilinogen with a monopyrrolic or dipyrrylmethane structure unless the pyrrole ring bears some substituent group whose influence on the position of the absorption maximum is opposite to those so far studied.

If it is accepted that porphobilinogen forms porphyrin and the yellow and violet pigments, one $\alpha$ position must carry a potential methyne, $-\mathrm{CH}=$, group the nature and effect on absorption of which is unknown. Pyrrolic substances react with the Ehrlich aldehyde reagent when they have an $\alpha$ position free or bearing a readily displaceable group which must be present if porphobilinogen has a monopyrrolic structure. However, tetrapyrrolic substances such as mesobilirubinogen which do not contain free $\alpha$ positions also react with $p$-dimethylaminobenzaldehyde, and such a tetrapyrrolic structure for porphobilinogen has also to be considered; mesobilirubinogen itself shows no absorption above $250 \mathrm{~m} \mu$. (unpublished observation).

Dipyrrylmethenes and other multipyrrolic structures containing conjugated pyrrole rings are all coloured and have prominent absorption maxima in the visible region (Pruckner \& Stern, 1937). The yellow pigment may well be a $5: 5^{\prime}$-disubstituted dipyrrylmethene, a structure in accord with its absorption spectrum, its green fluorescence with zinc salts, its apparent $\mathrm{pK}$ of 9 and its reduction by sodium amalgam to a colourless compound, but there may be additional non-conjugated pyrrole rings linked by methene, $-\mathrm{CH}_{2}-$, groups, giving tri- or tetra-pyrryl structures (cf. stercobilin (tetrahydromesobilene) or urobilin (mesobilene)). The absorption spectrum of the violet pigment suggests the presence of a more extensive system of double bonds than may be contained in a dipyrryl compound. The absence of a red fluorescence with zinc salts and the failure of sodium amalgam reduction to give a bilane reacting with Ehrlich's reagent, suggests that it is not a biliviolin or bilirhodin type of compound, i.e. a biladiene, biladienone or biladienediol.

\section{Evidence that porphobilinogen gives rise to porphyrin}

Porphyrin has been obtained in yields of $0.75-$ $2 \mu \mathrm{g}$. per unit of porphobilinogen in four cases of acute porphyria studied. These values agree well with those previously reported (Prunty, 1945; Gray, 1950). Differences in yields are probably explained by minor differences in technique. The maximum yields of porphyrin appear to be obtained on heating in $0.05-0.2 \mathrm{~N}-$ hydrochloric acid. It is probable that $\mathrm{pH} 5.2$ is optimal for porphyrin formation only when porphyria urines, and not porphobilinogen solutions, are being heated (Grieg et al. 1950).

It is difficult to reconcile with the work of Watson and co-workers and of Herbert (1952) our failure to demonstrate an ethyl acetate-soluble Ehrlich nonreacting porphyrin precursor in the cases studied, as well as our failure to obtain a porphobilinogen preparation incapable of forming porphyrin. Neither Watson nor Herbert has indicated the quantities of porphyrin formed from their ethyl acetate-soluble precursors.

Westall (1952) has attempted to separate porphobilinogen from a possible second precursor by paper partition chromatography. Five different solvent systems were used which gave widely differing $R_{F}$ values for the material reacting with Ehrlich's reagent. On spraying the paper with buffer and heating, porphyrin was found only in those areas of the paper to which the Ehrlichreacting substance had moved. We have confirmed his results, using a system with butanol saturated with $10 \%(w / v)$ acetic acid as the moving phase. Such behaviour supports the view that porphyrin is formed from porphobilinogen unless the porphyrin precursor moves on paper with the same $R_{F}$ value as porphobilinogen under these conditions. Insufficient material has been available to determine whether porphobilinogen purified by paper partition chromatography can also form the yellow and violet pigments.

It is possible that porphobilinogen is a mixture of two or more closely related chemical substances both reacting with the Ehrlich aldehyde reagent and which react to form porphyrin, yellow and violet pigments. Other precursors of porphyrin may also be excreted by patients with acute porphyria, but no evidence has been found of their presence in the cases we have studied.

\section{SUMMARY}

1. The changes occurring when porphobilinogen solutions were $(a)$ heated at $\mathrm{pH} 5.2$ and in hydrochloric acid and $(b)$ allowed to stand at $\mathrm{pH} 1$, have been studied spectrophotometrically.

2. The spectral absorption at 286-288 $\mathrm{m} \mu$. of porphobilinogen solutions as usually prepared has been shown to be due to uric acid.

3. Approximately $2 \mu \mathrm{g}$. of porphyrin per unit of porphobilinogen were obtained, the exact yield depending on the conditions of heating.

4. A yellow pigment was formed on heating, which absorbed maximally at $480 \mathrm{~m} \mu$. It is suggested that this is a $5: 5^{\prime}$-disubstituted dipyrrylmethene or a bilene. 
5. On standing at $\mathrm{pH} 1$ a violet pigment of unknown structure was formed which absorbed maximally at 503-505 $\mathrm{m} \mu$.

6. It has not been possible to separate a second precursor from porphyria urines.

7. The experiments reported, while not providing conclusive evidence, support the view that porphobilinogen itself can form porphyrin, yellow pigment and violet pigment according to the conditions.

We wish to express our thanks to Prof. C. Rimington for helpful discussions, and to the Medical Research Council for a personal grant to one of us (P.E.B.) and for an expenses grant to C.H.G.

Note. Since this paper was accepted for publication, crystalline porphobilinogen has been prepared from human acute porphyria urine (Westall, R. G. (1952), Nature, Lond., 170, 614). The results described in the present paper have been confirmed in every respect using crystalline material we have prepared by Westall's method, from the urine of rabbits in which porphyria had been induced by the administration of Sedormid (Schmid, R., quoted by Lowry, P. T., Hawkinson, V. \& Watson, C. J. (1952), Metabolism, 1, 149).

\title{
REFERENCES
}

Brockman, P. E. \& Gray, C. H. (1951). Biochem. J. 49, lxxi.

Brockman, P. E. \& Gray, C. H. (1952). 2nd Int. Congr. Biochem., Abstr., p. 212.

Cole, S. W. (1933). Practical Physiological Chemistry, 9th ed. p. 24. Cambridge: W. Heffer and Sons Ltd.

Dobriner, K., Strain, W. H. \& Localio, S. A. (1937). Proc. Soc. exp. Biol., N.Y., 36, 752.

Gray, C. H. (1950). Arch. intern. Med. 85, 459.

Gray, C. H. (1951). Biochem. J. 48, liv.

Grieg, A., Askevold, R. \& Sviensson, S. L. (1950). Scand. J. clin. Lab. Invest. $2,1$.

Hawkinson, V. E. \& Watson, C. J. (1952). Science, 115, 496. Herbert, F. K. (1952). Biochem. J. 52, xii.

Lowry, P. T., Schmid, R., Hawkinson, V. E., Schwartz, S. \& Watson, C. J. (1950). Bull. Univ. Minn. Hosp. 22, 97. Michaelis, L. (1931). Biochem. Z. 234, 139.
Neuberger, A., Muir, H. M. \& Gray, C. H. (1950). Nature, Lond., 165, 948.

Neuberger, A. \& Scott, J. J. (1952). Proc. Roy. Soc. A, 213, 307.

Praetorius, E. (1949). Scand. J. clin. Lab. Invest. 1, 222.

Pruckner, F. \& Dobeneck, H. (1942). Z. phys. Chem. A, 190, 43.

Pruckner, F. \& Stern, A. (1937). Z. phys. Chem. A, 180, 25.

Prunty, F. T. G. (1945). Biochem. J. 39, 446.

Sveinsson, S. L., Rimington, C. \& Barnes, H. D. (1949). Scand. J. clin. Lab. Invest. 1, 2.

Waldeström, J. \& Vahlquist, B. (1939a). Hoppe-Seyl. Z. 260, 189.

Waldenstörm, J. \& Vahlquist, B. (1939b). Hoppe-Seyl. Z. 259, 213.

Watson, C. J. (1951). Personal communication.

Westall, R. G. (1952). Personal communication.

\section{The Ammonia and Urea Excretion of Different Species of Amphibia during their Development and Metamorphosis}

\author{
By A. F. MUNRO \\ Department of Physiology, Marischal College, University of Aberdeen, and Department of Physiology, \\ King's College, University of London
}

(Received 16 July 1952)

Metamorphosis is a short but none the less oritical stage in the development of Amphibia during which extensive changes occur, enabling them to transfer from an aquatic to a more or less terrestrial habitat. The anatomical changes associated with the transition have been described by numerous workers, but the underlying chemical and metabolic transformations demanded by such changes are still largely obscure. The present paper deals with one aspect of nitrogen excretion during metamorphosis.

Some years ago the present author observed that metamorphosis in the common frog was characterized by a change in the chemical form in which nitrogen was excreted. The tadpole, up to the time of metamorphosis, excreted about 10 times more of its waste nitrogen as ammonia than as urea, while the frog excreted nitrogen mainly as urea. The changeover was accompanied by a corresponding increase in the concentration of liver arginase (Munro, 1939).

These changes are interesting because they are in harmony with the concept that the form in which waste nitrogen is excreted is governed by the type of environment, aquatic or terrestrial, within which the animal develops and later functions as an adult. Needham (1931) has collected data on the urinary nitrogen partition of a large number of animal 